\title{
Psychological Capital Research: A Meta-Analysis and Implications for Management Sustainability
}

\author{
Fanzhu Kong ${ }^{1}$, Cheng-Hung Tsai ${ }^{2}$, Fu-Sheng Tsai ${ }^{2, * \mathbb{C}}$, Wenyi Huang ${ }^{3}$ and \\ Shareena Malapitan de la Cruz ${ }^{2}$ \\ 1 Department of Business Administration, Huaiyin Institute of Technology, Huaian 223001, China; \\ tongjihrd@163.com \\ 2 Department of Business Administration, Cheng Shiu University, Kaohsiung 83347, Taiwan; \\ child@gcloud.csu.edu.tw (C.-H.T.); mcruz2018@outlook.com (S.M.d.1.C.) \\ 3 Postgraduate Programs in Management, I-Shou University, Kaohsiung 83347, Taiwan; \\ y550907@yahoo.com.tw \\ * Correspondence: tsaifs@gcloud.csu.edu.tw; Tel.: +886-7-731-0606
}

Received: 20 August 2018; Accepted: 25 September 2018; Published: 28 September 2018

\begin{abstract}
The purpose of this study is to conduct a wide-ranging meta-analytic review of empirical psychological capital studies in the management field. We conducted a meta-analysis on papers collected from the EBSCOhost and ProQuest databases. For comprehensive and extensive literature coverage, we also searched and compared the Journal Citation Report for the journals that referenced the most-cited articles (e.g., Journal of Organizational Behavior, Academy of Management Journal, etc.). A total of 81 published types of research were thoroughly selected and analyzed. The results revealed that, with different weighting, the following influencing factors have significant associations with psychological capital: organizational climate, organizational justice, authentic leadership, leader-member exchange, and occupational stress. Also, with different influencing weighting, psychological capital is confirmed to have impacts on job satisfaction, attitude, performance, organizational citizenship behavior, and undesirable behaviors. Implications for managerial sustainability are discussed.
\end{abstract}

Keywords: psychological capital; meta-analysis; influencing and influenced factors; sustainability

\section{Introduction}

Psychological capital (PC) denotes the affirmative mental state that manifests in personal stages of growth and development [1]. So far, it has been theoretically identified by Luthans and associates [2-5] as being composed of hope, optimism, efficacy, and resilience [6]. This hastens the need to understand the influencing and influenced factors for psychological capital in relation to employee and organization due to its impact on management sustainability.

The purpose of reviewing PC using meta-analysis was as a result of the need to desist from sitting back and waiting for disorders to develop within this field of study that has in the last few years seen the publication of many articles on the subject matter. Given the challenges that have been raised by the key authors in the field, we found it necessary to provide a wide-ranging quantitative review of published and unpublished studies that have been conducted in the last decade. We chose the meta-analysis method because of its capability to identify disorders in the field and address them in the right way by pinpointing areas of weakness. The study acknowledged the impact that potential disorders might have on employee outcomes. Another reason for reviewing PC using meta-analysis was the need to evaluate whether PC as a moderator could be utilized to explain the variability of the size effects that have been reported and identified from individual studies. Our focus was to utilize 
the meta-analysis method to provide a specific value of PC on employee performance management and human resource development in general.

\section{Literature Review}

Previous studies show a strong correlation between employees' outcomes and psychological capital. Bergheim et al. [7] claimed that PC influences between 10-12\% of the employees' perception about safety in three Norwegian shipping companies. The authors claim that the correlation is positive, meaning that whenever it increases, then employees' perception about their safety increases as well. Avey et al. [8] have established that because of the relationship between employees' measures of well-being and PC, then PC can be utilized to explain variance in the measures over time. Joya and Edan [9] on their part have established that PC can be utilized to manage employees' turnover intention, workplace deviance, and stress among employees. Luthans, Youssef, and Avolio [10] defined psychological capital (PC) as a positive mental developmental state of an individual that is characterized by resilience, hope, efficacy, and optimism.

The above different dimensions of psychological capital are measureable, open to development, and can be changed for more effective work performance [11]. Hope is considered to be a positive motivational state that is derived from senses of success based on pathways for meeting goals and energy directed toward achieving goals. On the other hand, optimism is considered particularly in positive psychology to be an explanatory behavior of interpreting off-putting events as temporal, external, and situation-specific, as well as a positive future expectation that is open to development [12]. Efficacy on its part is considered to be an in-built conviction within a person of his/her capabilities to mobilize cognitive resources, courses of action, and motivation that are required to perform a predetermined task within given contexts. Finally, resilience is considered to be the capacity of a person to rebound from conflicts, increased responsibilities, adversities, failures, or even challenges [2]. Since PC is composed of the four attributes, then it combines constructs from the attributes.

On the basis of the above attributes, then PC is a second-order factor, meaning that it can be understood better by evaluating the above attributes. Practically, today, PC is significant to several key workplace outcomes, such as individual attitudes, behaviors, satisfaction, and organizational performance [10]. Avey et al. [5] claimed that even if the attributes have been shown to be naturally discriminant, they have a lot in common that can be utilized to explain PC. Against such a backdrop constructed with existing academic literature and practical observations, our contribution is that this paper offers timely and updated meta-analysis-based information regarding the development of psychological capital research as a dynamic scientific field. Moreover, we offer the analyses into more different antecedents and consequences than could be found in an extant meta-analysis study of psychological capital. For example, in Avey et al.'s good work [5], the meta-analytical efforts were mainly on employee attitude, behavior, and performance (i.e., only individual-level outcomes). On the contrary, we have interpersonal level antecedents (e.g., leader-member exchange) and non-conventional outcomes (e.g., organizational citizenship behavior).

\section{Materials and Methods}

\subsection{Methodology}

The meta-analysis test was used to find out the key factors that influence psychological capital and its consequences factors. As a research method, it quantitatively assembles results from different empirical studies and tries to make sense of those studies [13]. For the sake of collecting information, meta-analysis is primary for the development of science, because meta-analysis procedures serve to overcome the research articles that occur in all of the individual experimental studies to draw correct academic conclusions [14].

Our goal in adopting such a method in this study is to specifically define and identify the factors that mostly affect and impact psychological capital. We thereby obtained effect-size indices from 
individual studies and coded characteristics for those studies to examine their connection with effect sizes. The analysis prompted us to weight effect estimates as functions of their precision by assuming that they were fixed on some statistical models, so that we could interpret their results [13].

\subsection{Data Set}

To obtain a comprehensive and extensive literature search for the term "psychological capital", we started by typing the term into the EBSCOhost database (1889-present) and ProQuest Advanced. Then, we searched the Journal Citation Report for the journals that referenced the most-cited articles in the organizational capabilities literature such as the Academy of Management Journal, Journal of Organizational Behavior, and Journal of Occupational and Organizational Psychology, among others. We did not impose a specific time span, because we wanted to gather as many studies as we could.

The process of selecting studies and research for this meta-analysis was based on several factors. First, the researcher chose empirical studies that satisfied the previously discussed definition of psychological capital and the topics that are related to the main factor. Second, we selected studies that had a big relationship with psychological capital, even if the main topic of the studies was not psychological capital. Lastly, we separated the studies that focused only on psychological capital compared to the four core factors of psychological capital, which are hope, resilience, self-efficacy, and optimism. This is to ensure the true significance of overall psychological capital compared to the core factors individually.

On the completion of the searching process, our comprehensive search identified 202 results from the database; however, only 145 items are said to be on the list due to some error of the database search engine. Out of the 145 results, only 116 actually exist. However, 29 journals are not listed in the Journal Citation Report, and six more of the 145 are also unusable because of a mismatch in topic area (e.g., having both "psychological" and "capital" on the title but not "psychological capital"). In total, there are only 81 literature studies that are usable in the database and can be useful in this study.

Among these studies, we only chose to include the 77 quantitative studies for the reason that qualitative studies do not include enough information such as coefficients in order to complete our desired results. To develop our final table, we followed the procedures outlined in a recent meta-analysis in the marketing literature (e.g., Lim 2010). We calculated the sample weighted correlation for each sample to obtain the ratio of correlation variance that was associated with the sample and sampling error (Hunter and Schmidt, 2004). The researcher also calculated the degrees of freedom (dr) and expected frequency counts. In the addition, Fisher's $\mathrm{Zr}$ was computed for a transformation of the sample correlation coefficient together with the Chi-square value for the studies. The Chi-square test helped us to estimate the standard error for effect sizes at a $95 \%$ confidence interval.

As a result, most of the researched antecedents and consequences of psychological capital were identified through the systematic above-mentioned processes. Table 1 presents the antecedents of psychological capital and the respective journals from where they were collected. Table 2 presents the consequences of psychological capital and the respective journals from where this information was collected.

Table 1. Journal source of the collected papers for psychological capital (PC)'s antecedents.

\begin{tabular}{ll}
\hline \multicolumn{1}{c}{ Antecedents } & \multicolumn{1}{c}{ Journal Name } \\
\hline A. Organizational Climate & $\begin{array}{l}\text { International Journal of Human Resource Management; Social Behavior and } \\
\text { Personality; BMC Public Health }\end{array}$ \\
\hline B. Organizational Justice & $\begin{array}{l}\text { Journal of Applied Psychology; Organizational Behavior and Human } \\
\text { Decision Processes }\end{array}$ \\
\hline C. Leader-Member Exchange & $\begin{array}{l}\text { BMC Public Health; International Journal of Human Resource Management; } \\
\text { Journal of Organizational Behavior; Personnel Psychology; }\end{array}$ \\
\hline D. Authentic Leadership & $\begin{array}{l}\text { Journal of Organizational Behavior; International Journal of Human Resource } \\
\text { Management; Journal of Business Research; Journal of Business Ethics }\end{array}$ \\
\hline E. Occupational Stress & BMC Health and Services Research; BMC Psychiatry; BMC Public Health \\
\hline
\end{tabular}


Table 2. Journal source of the collected papers for PC's consequence.

\begin{tabular}{lll}
\hline \multicolumn{1}{c}{ Antecedents } & \multicolumn{1}{c}{ Journal Name } \\
\hline A. Job Satisfaction & $\begin{array}{l}\text { Human Resource Development Quarterly; Journal of Organizational Behavior; } \\
\text { Personnel Psychology; Safety Science; }\end{array}$ \\
\hline B. Job Performance & $\begin{array}{l}\text { Journal of Business Ethics; Journal of Advanced Nursing; Journal of Business } \\
\text { Research; Social Behavior and Personality; Personnel Psychology; Journal of } \\
\text { Organizational Behavior; }\end{array}$ \\
\hline C. Job Attitude & $\begin{array}{l}\text { Human Resource Development Quarterly; Social Behavior and Personality; } \\
\text { Journal of Advanced Nursing; Safety Science; Human Resource Management; } \\
\text { Journal of Organizational Behavior; Journal of Happiness Studies }\end{array}$ \\
\hline D. Organizational & Citizenship Behavior & $\begin{array}{l}\text { PLOSOne; Human Resource Development Quarterly; BMC Psychiatry; Journal of } \\
\text { Organizational Behavior; Personnel Psychology; Public Personnel Management }\end{array}$ \\
\hline E. $\quad$ Undesirable Behavior & $\begin{array}{l}\text { Human Resource Development Quarterly; Journal of Organizational Behavior; } \\
\text { Personnel Psychology; }\end{array}$ \\
\hline
\end{tabular}

\section{Results and Discussions}

\section{Meta-Analysis for Significant Antecedents}

Based on the collected statistics, Table 3 provides the meta-analytic estimates of the factors of proposed antecedent factors toward psychological capital. As the data depicts, the organizational climate had a noteworthy, positive relationship with psychological capital on the basis of the sample-weighted mean correlation $(\check{\mathrm{r}}=0.502)$. After the measurement reliability and sampling error were corrected, which accounted for $2.14 \%$ of the effect-size variance across studies, the $95 \%$ confidence interval excluded zero, and the $Q$ statistics were found to be significant $\left(X^{2}=14.067, p<0.05\right)$. Similarly, organizational justice had a noteworthy, positive relationship with psychological capital on the basis of a sample-weighted mean correlation $(\breve{r}=0.633)$. Once again, after the measurement reliability and sampling error were corrected, which accounted for $2.21 \%$ of the effect-size variance, the $95 \%$ confidence interval excluded zero, and the $Q$ statistics were found to be significant $\left(X^{2}=11.07\right.$, $p<0.05)$. Leader-member exchange had a significant, positive relationship with psychological capital on the basis of a sample-weighted mean correlation ( $\breve{r}=0.397)$. After measurement reliability and the sampling error were corrected, which accounted for $2.42 \%$ of the effect-size variance, the $95 \%$ confidence interval excluded zero, and the $Q$ statistics were found to be significant $\left(X^{2}=7.815, p<0.05\right)$. Authentic leadership equally had a noteworthy positive relationship with psychological capital on the basis of sample-weighted mean correlation $(\check{\mathrm{r}}=0.637)$. After measurement reliability and sampling error were corrected, which accounted for $2.92 \%$ of the effect-size variance, the $95 \%$ confidence interval excluded zero and the $Q$ statistics were found to be significant $\left(X^{2}=9.488, p<0.05\right)$. Lastly, occupational stress was found to have a noteworthy positive relationship with psychological capital on the basis of sample-weighted mean correlation $(\check{\mathrm{r}}=0.338)$. After measurement reliability and sampling error were corrected, which accounted for $2.71 \%$ of the effect-size variance, the $95 \%$ confidence interval excluded zero, and the $Q$ statistics were found to be significant $\left(X^{2}=5.991, p<0.05\right)$.

As demonstrated by the above results, previous studies show that organizational climate has a significant impact on employees' performance. They depict that the type of leadership that is exercised by supervisors directly influences the relationship that supervisors develop with subordinate employees, and subsequently the way that they perform their duties. It is of great importance to note that organizational climate is significantly different from organizational culture. Therefore, it mediates the relationship between PC and the ways that subordinate employees perform their duties [15]. On its part, organizational Justice denotes the fairness of work outcomes as employees perceive them. On one hand, procedural justice concerns itself with the fairness of procedures that are utilized to determine outcome allocation, whereas interactional justice, on the other hand, concerns itself with the fairness of interpersonal relationships or among employees. From the above results, organizational justice has 
been found to have a strong positive correlation with PC, meaning that the more employees perceive it as just, the more likely they are to identify with an organization and vice versa.

Leader-member exchange (LMX), which is defined as a scheme of components and their relationships that involve members of a dyad and interdependent behavior patterns, has also been found to have a significant relationship with PC. Previous studies have demonstrated various forms of leadership such as self-leadership and transformative leadership as effective at enhancing cohesiveness and self-efficacy and promoting employee performance. As a result, it is no wonder that it correlates positively with PC, even if the relationship is moderately weak. Walumbwa et al. [16] have established that they depict four types of behaviors, namely: self-awareness, balanced processing, relational transparency, and internalized moral perspective. In doing so, they enable employees to improve their performance and be satisfied with their jobs. For a long time, most employees identified their places of work as major sources of stress in their lives due to long hours of work, uncertain job expectations, and heavy workloads. According to Head [17], the occupational stress emanating from places of work might increase illness susceptibility and reduced well-being among employees. The studies evaluated in this analysis demonstrated that occupational stress had a significant impact on psychological capital, and thereby could result in depression and its related symptoms. In contrast to our expectations, it had a positive correlation with PC, although this correlation was weak.

Furthermore, we collected information on the consequences of psychological capital. Based on the collected statistics, Table 4 depicts the meta-analytic estimates of the psychological capital toward the proposed consequences factors. Job satisfaction was found to have a significant, positive relationship with psychological capital on the basis of sample-weighted mean correlation $(\breve{\mathrm{r}}=0.533)$. After measurement reliability and sampling error were corrected, which accounted for $0.75 \%$ of the effect-size variance, the $95 \%$ confidence interval excluded zero and the $\mathrm{Q}$ statistics were found to be significant $\left(X^{2}=26.296, p<0.05\right)$. Similarly, job performance had a significant, positive relationship with psychological capital on the basis of sample-weighted mean correlation $(\check{\mathrm{r}}=0.326)$. After measurement reliability and sampling error, were corrected which accounted for $0.68 \%$ of the effect-size variance, the $95 \%$ confidence interval excluded zero, and the $Q$ statistics were found to be significant $\left(X^{2}=43.773\right.$, $p<0.05)$. At the same time, job attitude was also found to have a significant, positive relationship with psychological capital on the basis of sample-weighted mean correlation $(\check{r}=0.522)$. After measurement reliability and sampling error were corrected, which accounted for $0.5 \%$ of the effect-size variance, the $95 \%$ confidence interval excluded zero, and the $Q$ statistics were found to be significant $\left(X^{2}=43.773\right.$, $p<0.05)$. Furthermore, the organizational citizenship behavior was also found to have a significant, positive relationship with psychological capital on the basis of sample-weighted mean correlation $(\breve{\mathrm{r}}=0.431)$. After measurement reliability and sampling error were corrected, which accounted for $0.4 \%$ of the effect-size variance, the $95 \%$ confidence interval excluded zero, and the $Q$ statistics were found to be significant $\left(X^{2}=43.773, p<0.05\right)$. On the contrary, undesirable behavior was found to have a significant negative relationship with psychological capital on the basis of sample-weighted mean correlation $(\check{\mathrm{r}}=-0.376)$. After measurement reliability and sampling error were corrected, which accounted for $0.3 \%$ of the effect-size variance the $95 \%$ confidence interval excluded zero, and the $Q$ statistics were found to be significant $\left(X^{2}=24.996, p<0.05\right)$. 
Table 3. Antecedents factors' effect sizes on psychological capital.

\begin{tabular}{|c|c|c|c|c|c|c|c|c|c|c|c|}
\hline \multirow[b]{2}{*}{ Antecedent Factors } & \multirow[b]{2}{*}{$\mathbf{k}$} & \multirow[b]{2}{*}{$\mathbf{N}$} & \multirow[b]{2}{*}{$\check{\mathbf{r}}$} & \multirow[b]{2}{*}{$\mathrm{Zr}$} & \multicolumn{6}{|c|}{$95 \% \mathrm{CI}$} & \multirow[b]{2}{*}{$X^{2}(0.05)$} \\
\hline & & & & & $\% \mathrm{SE}$ & Weighted $\mathbf{r}$ & Lower & Upper & $\mathbf{Q}$ & df & \\
\hline Organizational Climate & 8 & 2187 & 0.502 & 0.484 & 0.021 & 0.450 & 0.408 & 0.492 & 171.859 & 7 & 14.067 \\
\hline Organizational Justice & 6 & 2053 & 0.633 & 0.716 & 0.022 & 0.614 & 0.571 & 0.657 & 94.487 & 5 & 11.07 \\
\hline Leader-Member Exchange & 4 & 1707 & 0.397 & 0.527 & 0.024 & 0.483 & 0.435 & 0.530 & 158.484 & 3 & 7.815 \\
\hline Authentic Leadership & 5 & 1175 & 0.637 & 0.655 & 0.029 & 0.575 & 0.518 & 0.632 & 72.199 & 4 & 9.488 \\
\hline \multirow[t]{2}{*}{ Occupational Stress } & 3 & 1367 & 0.386 & 0.351 & 0.027 & 0.338 & 0.285 & 0.391 & 8.565 & 2 & 5.991 \\
\hline & 26 & 8489 & 2.460 & 2.733 & 0.124 & 2.460 & 2.217 & 2.703 & 505.593 & 21 & 48.431 \\
\hline
\end{tabular}

Note: Each k per row is based on independent samples; however, some authors reported data on multiple outcomes (e.g., effects for one sample on organizational climate, organizational environment, and office workers). Thus, the total $\mathrm{k}$ per table may be higher or lower than the total number of independent samples reported in this meta-analysis. $\mathrm{k}=$ number of articles; $\mathrm{N}$ = sample size; $\mathrm{r}=$ effect size statistics; weighted $\mathrm{r}=$ mean of effect size statistics; $\mathrm{Q}=$ homogeneity analysis.

Table 4. Consequence factors effect sizes of psychological capital.

\begin{tabular}{|c|c|c|c|c|c|c|c|c|c|c|c|}
\hline \multirow[b]{2}{*}{ Consequence Factors } & \multirow[b]{2}{*}{$\mathbf{k}$} & \multirow[b]{2}{*}{$\mathbf{N}$} & \multirow[b]{2}{*}{$\check{\mathbf{r}}$} & \multirow[b]{2}{*}{$\mathrm{Zr}$} & \multirow[b]{2}{*}{$\%$ SE } & \multicolumn{4}{|c|}{$95 \% \mathrm{CI}$} & \multirow[b]{2}{*}{ df } & \multirow[b]{2}{*}{$X^{2}(0.05)$} \\
\hline & & & & & & Weighted $\mathbf{r}$ & Lower & Upper & $\mathbf{Q}$ & & \\
\hline Job Satisfaction & 16 & 17,447 & 0.533 & 0.534 & 0.008 & 0.488 & 0.518 & 0.547 & 194.038 & 15 & 26.296 \\
\hline Job Performance & 34 & 21,498 & 0.326 & 0.470 & 0.007 & 0.439 & 0.313 & 0.339 & 1350.33 & 33 & 43.773 \\
\hline Job Attitude & 25 & 20,977 & 0.522 & 0.508 & 0.007 & 0.468 & 0.508 & 0.535 & 843.823 & 24 & 43.773 \\
\hline Organization Citizenship Behavior & 31 & 39,739 & 0.431 & 0.606 & 0.005 & 0.542 & 0.421 & 0.441 & 6668.42 & 30 & 43.773 \\
\hline \multirow{2}{*}{ Undesirable Attitude } & 16 & 54,622 & -0.376 & -0.395 & 0.004 & -0.361 & -0.384 & -0.367 & 382.859 & 15 & 24.996 \\
\hline & 122 & 154,283 & 1.436 & 1.577 & 0.031 & 1.575 & 1.376 & 1.496 & 9439.48 & 117 & 182.611 \\
\hline
\end{tabular}

Note: Each k per row is based on independent samples; however, some authors reported data on multiple outcomes (e.g., effects for one sample on self-rate performance, supervisor-rate performance, satisfaction at work, in academia, or in organizations). Thus, the total $\mathrm{k}$ per table may be higher or lower than the total number of independent samples reported in this meta-analysis. $\mathrm{k}=$ number of articles; $\mathrm{N}=$ sample size; $\mathrm{r}=$ effect size statistics; weighted $\mathrm{r}=$ mean of effect size statistics; $\mathrm{Q}=$ homogeneity analysis. 
In line with the above results, previous studies have established a positive link between PC and job satisfaction $[8,18]$. No wonder some of the studies claim that PC is a better predictor of satisfaction in comparison to personality traits such as extraversion and conscientiousness [6]. PC is claimed to enhance employees' commitment to their organizations and jobs in general, and thereby plays a critical role in improving job satisfaction. As a result, due to its openness to development, PC can be utilized by managers to change the ways that employees perceive and perform their jobs [19]. Job performance on its part is a multi-dimensional construct that consists of different types of behaviors and actions. However, it correlates positively with PC, meaning that when employees perceive their organizations as hospitable to them, they improve the way that they perform their jobs. For this reason, as the study has established, the attitude that employees develop toward their jobs and employers in general play critical roles in management sustainability and job performance. According to Lee and Chen [20], it influences their continuance and effective commitment. The relationship between PC and work attitude is linear, meaning that when one increases, the other one increases as well, and vice versa. With regard to organizational citizenship behavior (OCB), previous studies have established that citizenship behaviors require extra effort, because they are not enforceable directly. As a result, it is the duty of management teams to promote them rather than attempt to enforce them. Finally, undesirable behaviors have been found to correlate negatively with PC, meaning that when PC lacks, then they develop, but when PC develops, they disappear from organizations. Nonetheless, such behaviors might develop due to job stressors, which should be minimized or eliminated from places of work.

\section{Conclusions and Discussions}

This study sorted the statistics collected from different but highly related studies of psychological capital, to offer an integrative analysis and results that may offer higher references for theoretical and practical development. Key findings follow. Organizational climate, organizational justice, leader-member exchange, authentic leadership as antecedents, and job satisfaction, attitude, and performance, as well as employee's organizational citizenship behavior and undesirable behavior as consequences of psychological capital, were all confirmatively re-examined based on dispersed statistics across those different empirical studies. As discussed in the above section, their effects relevant to psychological capital have been confirmed and revisited. It is especially noteworthy from the results that the interaction between the leader and a member will greatly affect the employees' psychological capital in every way possible, especially if the leader has an authentic leadership skill. The key characteristics of authentic leaders according to Avolio et al. [21] and Gardner et al. [22] are the openness and clarity of the behaviors that they demonstrate to employees, especially by sharing the information that is required in making critical decisions, providing feedback to employees on time, and accepting ideas from other people, especially subordinate employees. Moreover, psychological capital is proved to both positively affect organizational citizenship behavior and negatively affect the undesirable behaviors. Not all organizational capital can facilitate positive behavior and impede negative behaviors simultaneously. Our result confirmed that psychological capital is an intangible but powerful tool for affecting organizational behavior.

The research limitations can stimulate more future studies. First, this study uses meta-analysis and thus, collecting data from a database is crucial. The researchers have limited the search of statistics from Social Science Citation Index (SSCI)indexed papers in EBSCOHST and ProQuest, but there are still studies that are included in other databases. This study has provided strong evidence by using the meta-analysis method in terms of collecting relevant literature from the previous study of psychological capital. However, the research only used two databases, and ideally future research that continued this study ought to provide literature from other different databases. This would expand the collected literature and also establish a stronger result for the antecedent and consequence factors of psychological capital. Second, further research should strive to compare each psychological capital sub-construct to the antecedent and consequent construct provided by this study. This is to determine 
the appropriate measures regarding hope, reliability, self-efficacy, and optimism toward each factor of the construct. Furthermore, we suggest that future studies, even in different scientific disciplines, could take reference of this present study. For instance, studies adopting a salutogenic approach, which are the most beneficial for health promotion, will benefit from a better knowledge of the PC construct [23]. Applications of this paper in the field of workplace health promotion are appreciated. Another element that could be interesting for readers is the geographical distribution of the selected articles. Studies are still conducted only in a limited part of the world, which is surprising in a globalized economy. Future studies could discuss this phenomenon and indicate possible solutions, e.g., greater accessibility of PC measurement tools, translation into other languages, and trans-cultural validation, etc. (the authors thank a reviewer for such a wonderful suggestion about future research directions).

Overall, the study has established that the evidence that has been accumulated from previous studies show that psychological capital, which consists of resilience, efficacy, optimism, and hope, has a relatively strong positive relationship with job satisfaction, attitude, performance, and organization citizenship behaviors among employees. On the contrary, it has established that psychological capital relates negatively to undesirable job attitudes. More importantly, it has established that organizational climate, justice, leader-member exchange, and authentic leadership play significant roles in enhancing the development of psychological capital. As a result, in terms of implications, management teams should promote organizational justice, create good climates in their respective organizations, and relate in the right way with employees to promote the development and advancement of psychological capital in their organizations. The approach would, in turn, improve job satisfaction, performance, and promote organizational citizenship behaviors among employees. In so doing, it would minimize turnover intentions, stress, and anxiety among employees.

Author Contributions: F.K. acquired the funding support and write for the original draft; C.-H.T. wrote for the original draft and share the work of data analysis; F.-S.T. constructed the overall research framework, reviewed and thoroughly edited the original manuscript; W.H. reviewed and edited the manuscript; S.M.d.I.C. is the data collector and analyzer.

Funding: This paper is partially supported by Qing Lan Project of Jiangsu Province, China (Z302E16205).

Conflicts of Interest: The authors declare no conflict of interest.

\section{References}

1. Liu, L.; Xu, X.; Wu, H.; Yang, Y.; Wang, L. Associations of psychological capital, demographic and occupational factors with cigarette smoking among Chinese underground coal miners. BMC Public Health 2015, 15, 20. [CrossRef] [PubMed]

2. Luthans, F. The need for and meaning of positive organizational behavior. J. Organ. Behav. 2002, 23, 695-706. [CrossRef]

3. Luthans, F.; Youssef, C.M. Human, social, and now positive psychological capital management. Organ. Dyn. 2004, 33, 143-160. [CrossRef]

4. Youssef, C.M.; Luthans, F. Positive Organizational Behavior in the workplace: The Impact of Hope, Optimism, and Resilience. J. Manag. 2007, 33, 774-800. [CrossRef]

5. Avey, J.B.; Reichard, R.J.; Luthans, F.; Mhatre, K.H. Meta-Analysis of the Impact of Positive Psychological Capital on Employee Attitudes, Behaviors, and Performance. Hum. Resour. Dev. Q. 2011, 22, 127-152. [CrossRef]

6. Luthans, F.; Avolio, B.; Avey, J.B.; Norman, S.M. Positive Psychological Capital: Measurement and relationship with performance and satisfaction. Pers. Psychol. 2007, 60, 541-572. [CrossRef]

7. Bergheim, K.; Eid, J.; Hystad, S.W.; Nielsen, M.B.; Mearns, K.; Larsson, G.; Luthans, B. The Role of Psychological Capital in Perception of Safety Climate among Air Traffic Controllers. J. Leadersh. Organ. Stud. 2013, 20, 232-241. [CrossRef]

8. Luthans, F.; Avey, J.B.; Avolio, B.J.; Peterson, S.J. The Development and Resulting Performance Impact of Positive Psychological Capital. Hum. Resour. Dev. Q. 2010, 21, 41-67. [CrossRef] 
9. Joya, A.I.; Edan, M.A. Psychological Capital as a Moderator between Justice Types and Outcomes. J. Bus. Manag. Econ. Stud. 2016, 1, 14-32.

10. Luthans, F.; Youssef, C.M.; Avolio, B.J. Psychological Capital; Oxford University Press: New York, NY, USA, 2007.

11. Ding, Y.; Yang, Y.; Yang, X.; Zhang, T.; Qiu, X.; He, X.; Wang, W.; Wang, L.; Sui, H. The Mediating Role of Coping Style in the Relationship between Psychological Capital and Burnout among Chinese Nurses. PLoS ONE 2015, 10, e0122128. [CrossRef] [PubMed]

12. Seligman, M.E. Learned Optimism; Pocket Books: New York, NY, USA, 1998.

13. Sanchez-Meca, J.; Martin-Martinez, F. Meta-analysis in Psychological Research. Int. J. Psychol. Res. 2010, 3, 151-163. [CrossRef]

14. Hamilton, M.A.; Hunter, J.E. A framework for understanding: Meta-analysis of the persuasion literature. In Persuasion: Advances through Meta-Analysis; Allen, M., Priess, R.W., Eds.; Hampton Press: New York, NY, USA, 1998.

15. Qadeer, F.; Hina, J. Mediation of Psychological Capital between Organizational Climate and Organizational Citizenship Behavior. Pak. J. Commer. Soc. Sci. 2014, 8, 452-470.

16. Walumbwa, F.O.; Avolio, B.J.; Gardner, W.L.; Wernsing, T.S.; Peterson, S.J. Authentic leadership: Development and analysis of a multidimensional theory-based measure. J. Manag. 2008, 34, 89-126.

17. Head, J.K. Effort-reward imbalance and relational injustice at work predict sickness absence. J. Psychosom. Res. 2007, 63, 433-440. [CrossRef] [PubMed]

18. Luthans, F.; Norman, S.M.; Avolio, B.J.; Avey, J.B. The mediating role of psychological capital in the supportive organizational climate-employee performance relationship. J. Organ. Behav. 2008, 29, 219-238. [CrossRef]

19. Fu, J.S. Improving job satisfaction of Chinese doctors: The positive effects of perceived organizational support and psychological capital. Public Health 2013, 127, 946-951. [CrossRef] [PubMed]

20. Lee, C.C.; Chen, C.J. The Relationship between Employee Commitment and Job attitude and Its Effect on Service Quality in the Tourism Industry. Am. J. Ind. Bus. Manag. 2013, 3, 196-208. [CrossRef]

21. Avolio, B.J.; Zhu, W.; Koh, W.; Bhatia, P. Transformational leadership and organizational commitment: Mediating role of psychological empowerment and moderating role of structural distance. J. Organ. Behav. 2004, 25, 951-968. [CrossRef]

22. Avolio, B.J.; Gardner, W.L. Authentic leadership development: Getting to the root of positive forms of leadership. Leadersh. Q. 2005, 16, 213-338. [CrossRef]

23. Magnavita, N. Obstacles and Future Prospects: Considerations on Health Promotion Activities for Older Workers in Europe. Int. J. Environ. Res. Public Health 2018, 15, 1096. [CrossRef] [PubMed] 